American Journal of Environmental Sciences 6 (3): 280-285, 2010

ISSN 1553-345X

C 2010 Science Publications

\title{
A Two-Dimensional Wave Prediction Model Along the Best Track of Typhoon Linda 1997
}

\author{
${ }^{1}$ Worachat Wannawong, ${ }^{1}$ Usa W. Humphries, ${ }^{2}$ Prungchan Wongwises, \\ ${ }^{3}$ Suphat Vongvisessomjai and ${ }^{4}$ Wiriya Lueangaram \\ ${ }^{1}$ Department of Mathematics, Faculty of Science, \\ ${ }^{2}$ The Joint Graduate School of Energy and Environment, \\ King Mongkut's University of Technology Thonburi, Bangkok 10140, Thailand \\ ${ }^{3}$ Team Consulting Engineering and Management Co., Ltd., 151TEAM Building, \\ Nuan Chan Road, Bueng Kum, Bangkok 10230, Thailand \\ ${ }^{4}$ Meteorological Division, Department of Hydrographic, Royal Thai Navy, \\ Sattahip, Chonburi 20180, Thailand
}

\begin{abstract}
Problem statement: A two-dimensional wave prediction model along the best track of Typhoon Linda 1997 was interested to study the impact of typhoon wind-wave characteristics. The dynamical wave model with deep water condition was used to predict the wave height (Hs) of Typhoon Linda before and after entering into the Gulf of Thailand (GoT). Approach: The standard one-way nested grid for a regional scale of the third generation WAve Model Cycle 4 (WAMC4) is scrutinized in the present study. This model is enabled to solve the spectral energy balance equation on a coarse resolution grid in order to produce boundary conditions for a small area by the nested grid technique along the best track of typhoon. The model takes full advantage of the fine resolution wind fields in space and time produced by the available US Navy Operational Global Atmospheric Prediction System (NOGAPS) model with $1^{\circ}$ resolution. The nested grid application was developed in order to gradually increase the resolution from the open ocean towards the South China Sea (SCS) and the Gulf of Thailand (GoT) respectively. Results: The model results were predicted at five stations which were before and during the typhoon entering into the GoT. The wind speeds of the stations 1-5 were in ranges of 5.14-29.81, 4.11-28.27, 0.51-24.67, 0.51-31.35 and 0.51-33.41 m sec ${ }^{-1}$, respectively. While the $\mathrm{Hs}$ of these stations were found in ranges of $0.54-2.99,0.68-2.85,0.11-1.57,0.12-2.92$ and 0.09-2.76 m, respectively. The model results were compared with buoy observations at Ko-Chang and Rayong locations in the GoT which were obtained from the Seawatch project. The comparison of those results at Ko-Chang and Rayong showed the percentage errors of 11.20 and $15.12 \%$ respectively. Conclusion: The model results presented the relationship of typhoon wind-induced ocean wave at five stations along the best track. The tendency of the Hs from the model in the spherical coordinate propagation with deep water condition in the fine grid domain was in good agreement with the Hs from the observations.
\end{abstract}

Key words: Wave prediction, best track, Typhoon Linda, wave characteristics, spectral energy balance equation

\section{INTRODUCTION}

A two-dimensional wave prediction model has been developed by the Meteorological Department of Thailand and Royal Thai Navy since 1997. The wave prediction model is designed to provide the ocean wave forecasting for the Gulf of Thailand (GoT). It uses the two-step one-way nested grid from the Coarse Grid
Domain (CGD) covering the South China Sea (SCS) and the Fine Grid Domain (FGD) covering the GoT. The deep water conditions are applied in both domains. In the present study, the wave characteristics were important to predict the dynamics in the FGD along the best track which obtained from the Joint Typhoon Warning Centre (JTWC). The station points of the FGD (Fig. 1) in the three nested grid windows were designed

Corresponding Author: Worachat Wannawong, Department of Mathematics, Faculty of Science, King Mongkut's University of Technology Thonburi, Bangkok 10140, Thailand 
in order to study the impact of wind and wave along with the positions of the best track. The modeling system was applied to obtain the typhoon wave predictions in the regional seas, for example, the SCS and GoT. The regional implementations of the third-generation WAve Model Cycle 4 (WAMC4) have been reported in several studies (Gunther et al., 1992; Hasselmann et al., 1973; 1988). The WAMC4 model has been carried out and tested in the GoT with Typhoon Linda 1997 cases (Wannawong et al., 2010a; 2010b; 2011). The nested grid of two-step application of the WAMC4 model has been developed in order to gradually increase the resolution from the open sea towards the GoT region (Wannawong et al., 2010a). Gomez-Lahoz and Carretero-Albiach (1997) reported that the resolution increased by using the two-way nesting scheme developed at Puertos del Estado in the Spanish coast without resorting to high resolution in deep water. The two-step application of the previous study (Wannawong et al., 2010a) was a simple scheme and less computational effort. In the present study, the three steps of the nested grids (Wannawong et al., 2010b; 2011) which were only considered in the FGD along the best track are shown in Fig. 1. The objective of this study was to present the relationship of wind-wave interaction in the fine resolution wind fields in space and time produced by the available US Navy Operational Global Atmospheric Prediction System (NOGAPS) model with $1^{\circ}$ resolution (Hogan and Rosmond, 1991).

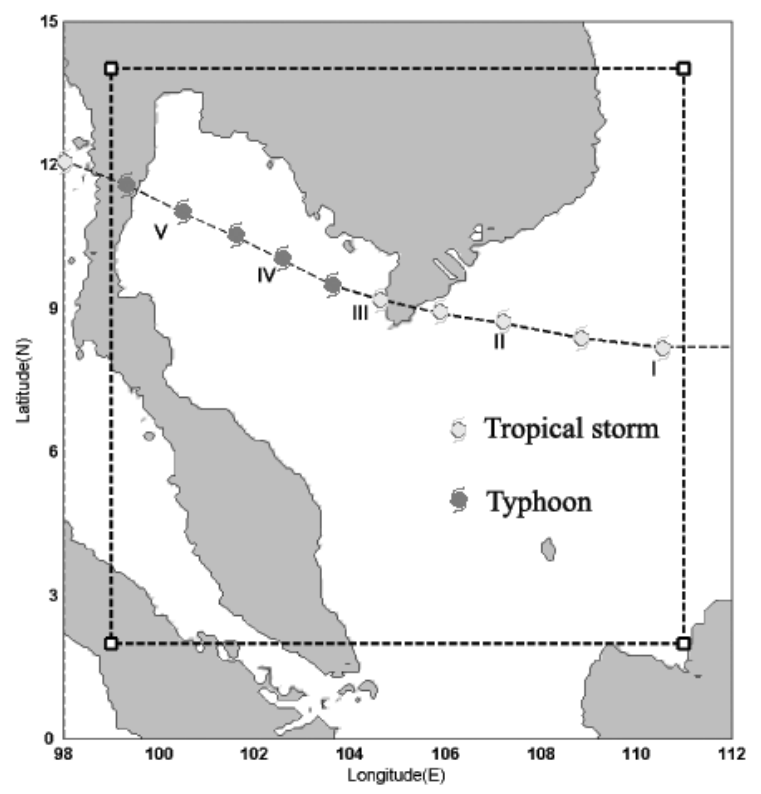

Fig. 1:The stations I, II, III, IV and V along the best track of Typhoon Linda 1997

\section{MATERIALS AND METHODS}

Model description: The spectral energy balance equation is a wave transport equation which is solved by the numerical methods of the WAMC4 model (Gunther et al., 1992; Hasselmann et al., 1973; 1988). The model can be used in the global, regional and coastal scales with terms of the discrete energy density (Wittmann and Farrar, 1997), F (t, x, f, $\theta$ ), where $\mathrm{t}$ represents time, $\mathrm{x}$ represents the geographical space in spherical coordinates $(\lambda, \phi)$ and $(\theta, f)$ represents the spectral space (direction and frequency). The wave direction $\theta$ represents the wave direction measured clockwise from the true north. In the absence of diffraction and currents, the governing equation of WAMC4 model is:

$\frac{\partial \mathrm{F}}{\partial \mathrm{t}}+\frac{\partial\left(\mathrm{c}_{\lambda} \mathrm{F}\right)}{\partial \lambda}+(\cos \phi)^{-1} \frac{\partial\left(\mathrm{c}_{\phi} \cos \phi\right) \mathrm{F}}{\partial \phi}+\frac{\partial\left(\mathrm{c}_{\theta} \mathrm{F}\right)}{\partial \theta}=\mathrm{S}_{\mathrm{tot}}$

Where:

$c_{\lambda}$ and $c_{\phi}=$ The propagation velocities of the group velocity

$\mathrm{c}_{\mathrm{g}} \quad=$ The geographical space

$\mathrm{c}_{\theta}=$ The propagation velocity in the spectral space

The left hand side of the Eq. 1 is applied in the regional scale with the absence of diffraction and currents. It represents the local changing rate of the wave energy density in time, propagation in the geographical space, shifting of frequency and refraction due to the spatial variation of depth and current. For the right hand side of the Eq. 1, $\mathrm{S}_{\text {tot }}$ shows effects of generation and dissipation of the waves in deep water including wind input $\left(\mathrm{S}_{\mathrm{in}}\right)$, white capping in dissipation $\left(\mathrm{S}_{\mathrm{ds}}\right)$ and nonlinear quadruplet wave-wave interactions $\left(\mathrm{S}_{\mathrm{nl}}\right)$.

Model setting and implementation: The twodimensional wave prediction model contained three domains covering the Pacific Ocean, SCS and GoT respectively (Wannawong et al., 2010a; 2010b; 2011). For the one-way nesting scheme mentioned earlier, the resolution of the Pacific application with closed ocean was increased from $0.5^{\circ}$ in the CGD of Typhoon Linda cases. The open sea of the SCS in deep water condition showed the resolution of $0.375^{\circ}$ in the Intermediate Grid Domain (IGD). The modeling system with the open sea condition of the GoT is set up to $0.250^{\circ}$ in the FGD. The CGD was closed to cover the typhoon wave generation from $95^{\circ} \mathrm{E}-155^{\circ} \mathrm{E}$ in longitude and from $20^{\circ} \mathrm{S}-40^{\circ} \mathrm{N}$ in latitude, which provided $121 \times 121$ points 
for both latitude and longitude. The IGD was opened to cover from $98^{\circ} \mathrm{E}-125^{\circ} \mathrm{E}$ and $2^{\circ} 8 \mathrm{~S}-25^{\circ} \mathrm{N}$ in longitude and latitude, respectively, which gave $109 \times 109$ points for both latitude and longitude. Finally, the FGD was opened to cover from $99^{\circ} \mathrm{E}-111^{\circ} \mathrm{E}$ in longitude and from $2^{\circ} \mathrm{N}-14^{\circ} \mathrm{N}$ in latitude, which gave $49 \times 49$ points for both latitude and longitude. Along the best track of Typhoon Linda, the application also has variable grid spaces of 1800, 1200 and $600 \mathrm{~s}$ in the CGD, IGD and FGD (Wannawong et al., 2010a; 2010b; 2011) respectively. The best track of Typhoon Linda in the FGD is presented in Fig. 1. The computations of wind speed and $\mathrm{Hs}$ at the positions of the best track are shown in Table 1. The two-dimensional wave prediction model required the bathymetry data and input wind field in each nested grid. The bathymetry data was obtained from ETOPO5 (Edwards, 1989) and ETOPO1 (Amante and Eakins, 2008). The ETOPO5 was updated in June 2005 for the acceptable deep water and has been applied in the CGD. The ETOPO1 (Bedrock version) was the latest version developed on July 28, 2008. It was chosen to apply in the IGD and FGD. The details of merging of both topographies and nested grid domains have been reported in several studies (Wannawong et al., 2010a; 2010b; 2011). The wind fields at $10 \mathrm{~m}$ height were obtained from the US Navy Operational Global Atmospheric Prediction System (NOGAPS) model with $1 \times 1$ data resolution and the linear interpolation was used to generate the wind data to the grid points (Hogan and Rosmond, 1991). The computational model of Typhoon Linda cases was started at 00UTC on October 20 and ended at 00UTC on November 10, 1997. The results of the twodimensional wave prediction model were expressed in every hour from the typhoon wave generation in the Pacific Ocean through the GoT. The stability of model was computed according to the Courant-FriedrichsLewy (CFL) stability condition.

\section{RESULTS AND DISCUSSION}

The computations of typhoon wind-wave along the best track were analyzed from a set up of positions as described in Table 1 and Fig. 1. The numerical prediction of wind-wave generated by Typhoon Linda at Station I was firstly considered. The strong wind-wave and its directions were presented in Fig. 2. The maximum and minimum of Hs related with the maximum and minimum of wind speed at Stations 5-5 are shown in Fig. 2-6 and Table 1.

Table 1: The computational of Wind Speed (WSP) and wave Height (Hs) along the position of the best track of JTWC

\begin{tabular}{|c|c|c|c|c|c|c|}
\hline Station & $\begin{array}{l}\text { JTWC position } \\
\text { Date/time (UTC) } \\
\text { YY-MM-DD-HH }\end{array}$ & $\begin{array}{l}\text { (Lo, Lat) } \\
\left({ }^{\circ} \mathrm{E},{ }^{\circ} \mathrm{N}\right)\end{array}$ & $\begin{array}{l}\text { Computation position } \\
\text { WSP (Max.) } \\
\left(\mathrm{m} \mathrm{s}^{-1}\right)\end{array}$ & $\begin{array}{l}\text { (Lon, Lat.) } \\
\left({ }^{\circ} \mathrm{E},{ }^{\circ} \mathrm{N}\right)\end{array}$ & $\begin{array}{l}\text { WSP (Min-Max.) } \\
\left(\mathrm{m} \mathrm{sec}^{-1}\right)\end{array}$ & $\begin{array}{l}\text { Hs (Mi-Max) } \\
(\mathrm{m})\end{array}$ \\
\hline $\mathrm{I}$ & 97110112 & $110.5,8.20$ & 25.70 & $110.50,8.25$ & $5.14-29.81$ & $0.54-2.99$ \\
\hline II & 97110200 & $107.2,8.70$ & 28.27 & $107.25,8.75$ & $4.11-28.27$ & $0.68-2.85$ \\
\hline III & 97110212 & $104.6,9.20$ & 28.27 & $104.50,9.25$ & $0.51-24.67$ & $0.11-1.57$ \\
\hline IV & 97110300 & $102.6,10.0$ & 33.41 & $102.50,10.0$ & $0.51-31.35$ & $0.12-2.92$ \\
\hline V & 97110312 & $100.5,11.0$ & 33.41 & $100.50,11.0$ & $0.51-33.41$ & $0.09-2.76$ \\
\hline
\end{tabular}
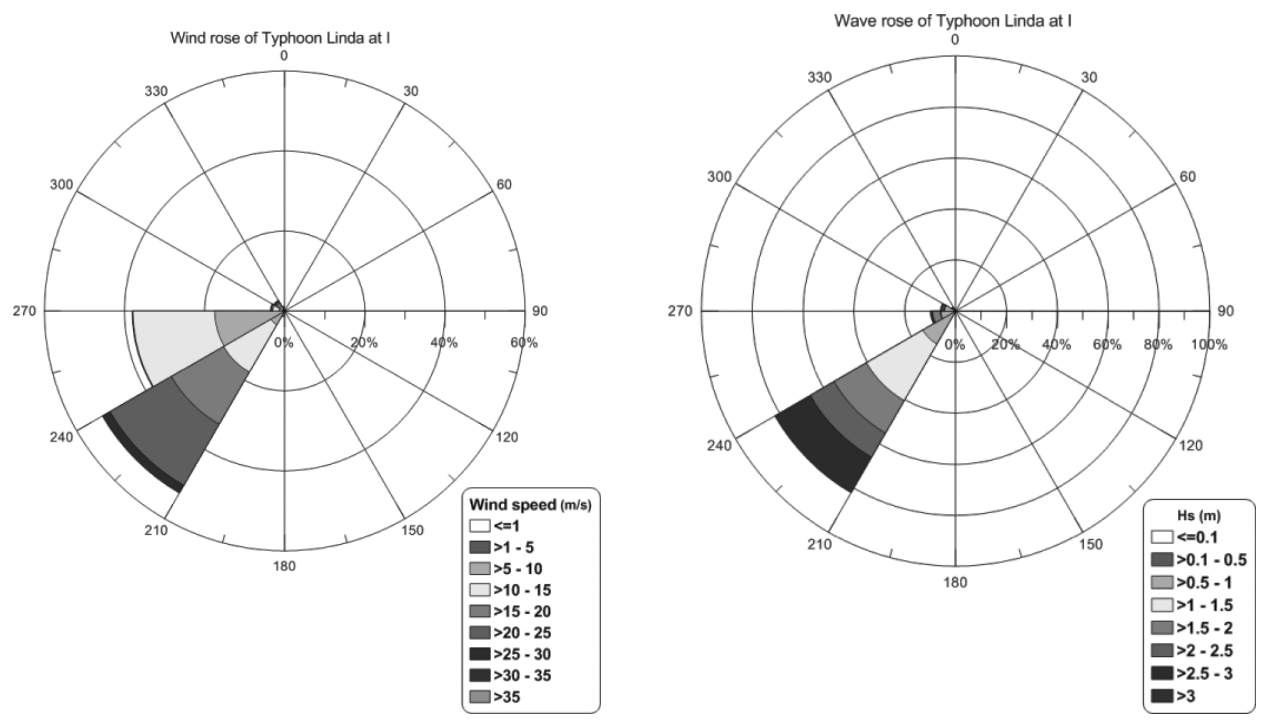

Fig. 2: The relation of wind speed $\left(\mathrm{m} \mathrm{sec}^{-1}\right)$ and $\mathrm{Hs}(\mathrm{m})$ at station 1 
Am. J. Environ. Sci., 6 (3): 280-285, 2010
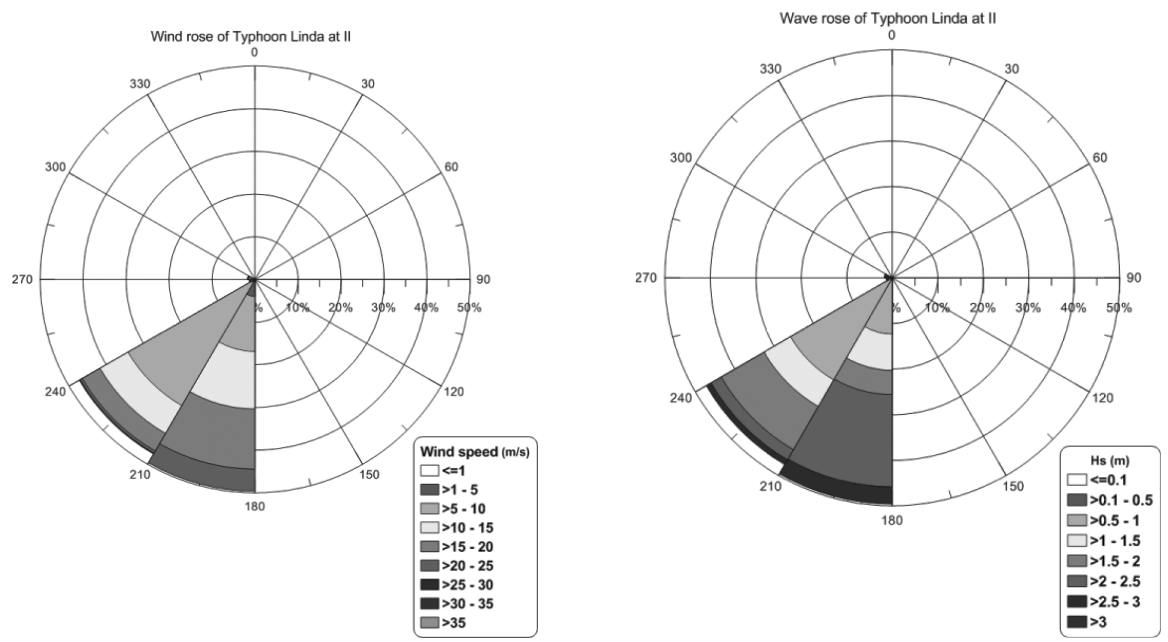

Fig. 3: The relation of wind speed $\left(\mathrm{m} \mathrm{sec}^{-1}\right)$ and $\mathrm{Hs}(\mathrm{m})$ at station 2
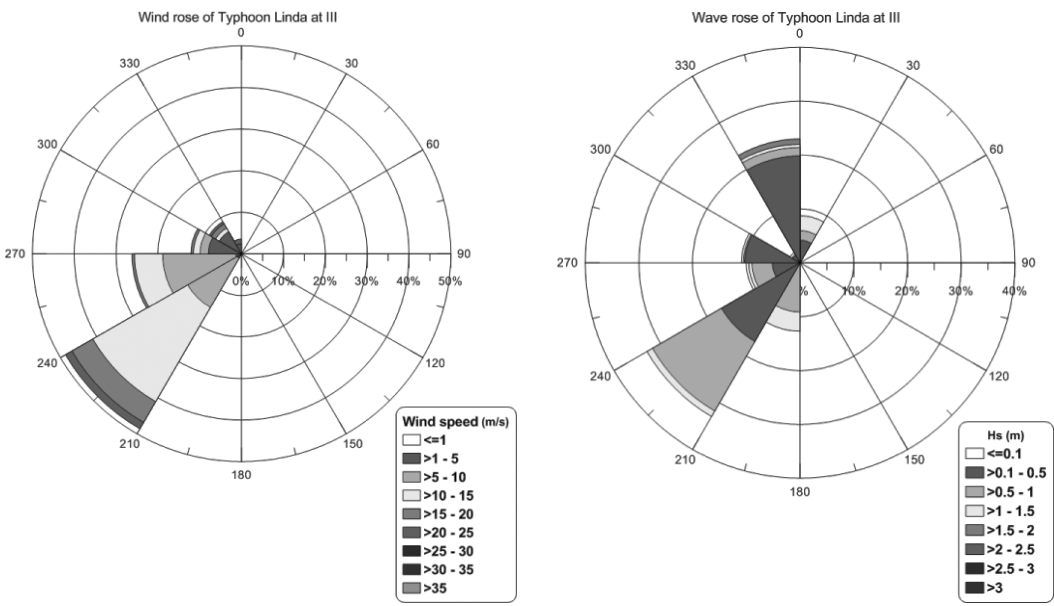

Fig. 4: The relation of wind speed $\left(\mathrm{m} \mathrm{sec}^{-1}\right)$ and $\mathrm{Hs}(\mathrm{m})$ at station 3
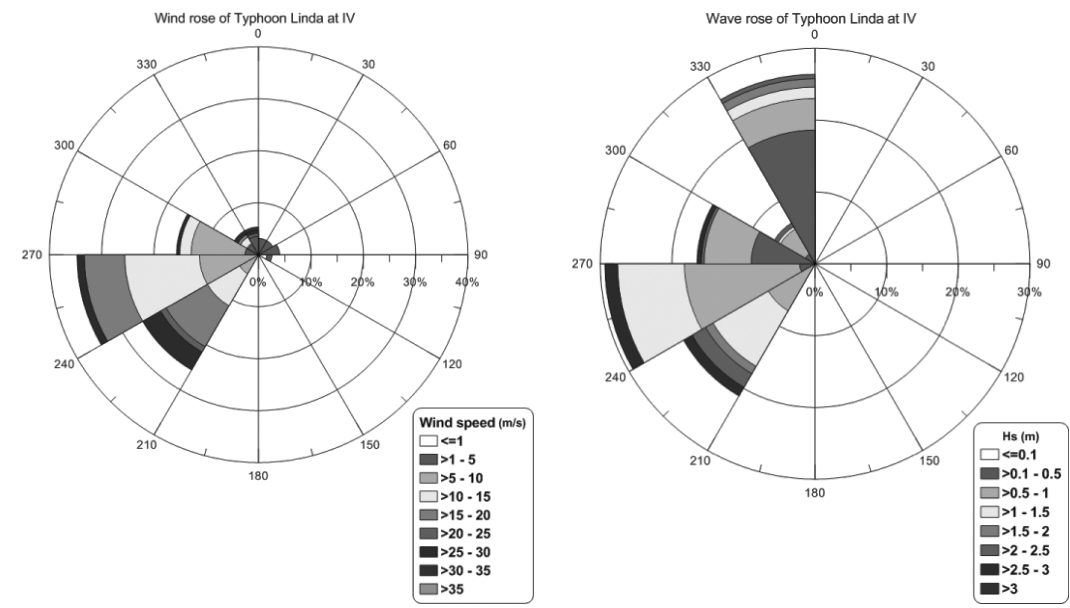

Fig. 5: The relation of wind speed $\left(\mathrm{m} \mathrm{sec}^{-1}\right)$ and $\mathrm{Hs}(\mathrm{m})$ at station 4 

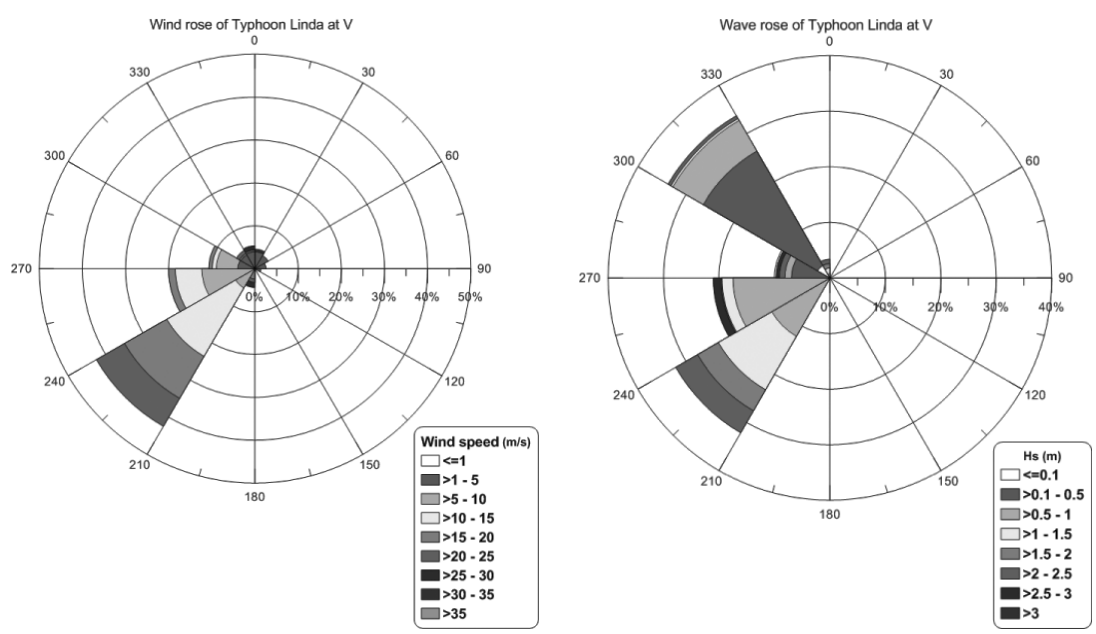

Fig. 6: The relation of wind speed $\left(\mathrm{m} \mathrm{sec}^{-1}\right)$ and $\mathrm{Hs}(\mathrm{m})$ at station 5

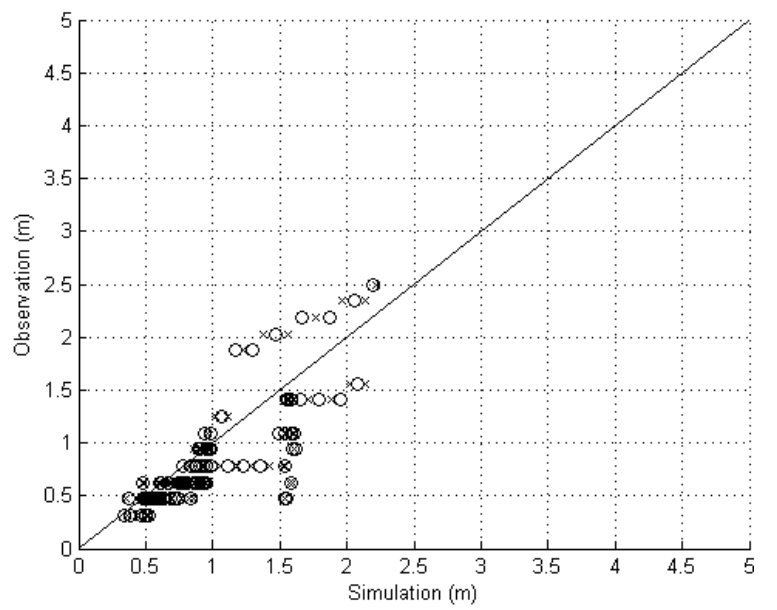

Fig. 7: The direct comparison of model (x) and measured Hs (o) during 1700UTC on October 31-1600UTC on November 8, 1997 at KoChang buoy

The direct comparison of the WAMC4 model (x) and measured Hs (o) during 1700UTC on October 311600UTC on November 8, 1997 showed that the simulated and observed $\mathrm{Hs}$ at Ko-Chang buoy were in ranges of 0.34-2.22 and 0.31-2.50 m, respectively (Fig. 7). While the simulated and observed Hs at Rayong buoy were found to be 0.33-2.52 and 0.16-2.97 m, respectively (Fig. 8).

In the present study, the simulated Hs shown in KoChang and Rayong buoys were not much different from those of the observational data. The comparison of the simulated and observed Hs at Ko-Chang and Rayong buoys showed the percentage errors of 11.20 and $15.12 \%$ respectively.

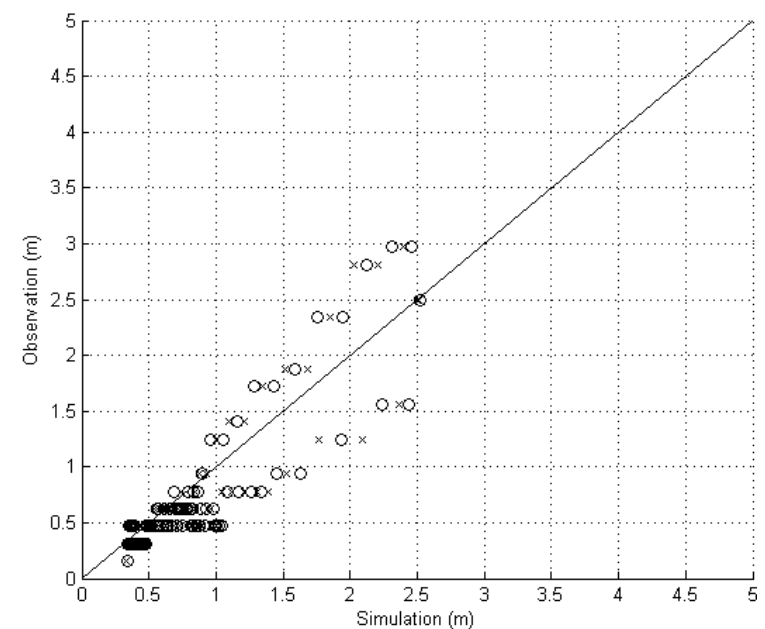

Fig. 8: The direct comparison of model (x) and measured Hs (o) during 1700UTC on October 31-1600UTC on November 8, 1997 at Rayong buoy

\section{CONCLUSION}

The present study was studied on the characteristics of typhoon wind-wave along the best track which showed the impact of wave water. The typhoon waves in the regional scales of the wave prediction are important to study. The results of this study indicated that the relationship of the wind-wave must be investigated and developed simultaneously. The results of the two-dimensional wave prediction model showed the slight difference of the Hs at KoChang and Rayong buoys with typhoon distribution during Typhoon Linda entering into the GoT. 
Additional studies will be undertaken in the future with a focus on impact of typhoon wind-wave on other domains and the two-dimensional wave prediction model should be coupled with the hydrodynamic models. The effects of typhoon wind-wave on sea surface layer should be more comprehensively examined with more typhoon case predictions.

\section{ACKNOWLEDGMENT}

The researchers would like to acknowledge the Commission on Higher Education for kindly providing financial support to Mr. Worachat Wannawong under the Strategic Scholarships Fellowships Frontier Research Networks in 2007. The authors are grateful to the Geo-Informatics and Space Technology Development Agency (GISTDA) for buoy data and documents. We also wish to thanks the Meteorological Division, Hydrographic Department, Royal Thai Navy, Thailand, for providing laboratory space. Finally, we are greatly indebted to Mr. Michael Willing and Miss Donlaporn Sae-tae for helpful comments on English grammar and usage.

\section{REFERENCES}

Amante, C. and B.W. Eakins, 2008. ETOPO1 1 arcminute global relief model: Procedures, data sources and analysis. NOAA.

Edwards, M.O., 1989. Global gridded elevation and bathymetry on 5 mine geographic grid (ETOPO5). NOAA.

Gomez-Lahoz, M. and J.C. Carretero-Albiach, 1997. A two-way nesting procedure for the WAM model: Application to the Spanish coast. Trans. Am. Soc. Mech. Eng., 119: 20-24.
Gunther, H., S. Hasselmann and P.A.E.M. Janssen, 1992. The WAM model cycle 4 (revised version). Rechenzentrum.

Hasselmann, K., T.P. Barnett, E. Bouws, H. Carlson and D.E. Cartwright et al., 1973. Measurements of wind-wave growth and swell decay during the Joint North Sea Wave Project (JONSWAP). Dtsch. Hydrogr. Zeitschrift, 12: 95-95.

Hasselmann, S., K. Hasselmann, E. Bauer, P.A.E.M. Janssen and G.J. Komen et al., 1988. The WAM model-A third generation ocean wave prediction model. J. Phys. Ocean., 18: 1775-1810.

Hogan, T.F. and T.E. Rosmond, 1991. The description of the navy operational global atmospheric system's spectral forecast model. Month. Weather. Rev., 119: 1786-1815.

Wannawong, W., U.W. Humphries, P. Wongwises, S. Vongvisessomjai and W. Lueangaram, 2010a. A numerical study of two coordinates for energy balance equations by wave model. Thai J. Math., 1: 197-214.

Wannawong, W., U.W. Humphries, P. Wongwises, S. Vongvisessomjai and W. Lueangaram, 2010b. Numerical analysis of wave and hydrodynamic models for energy balance and primitive equations. J. Math. Stat. Sci., 2: 140-150.

Wannawong, W., U.W. Humphries, P. Wongwises and S. Vongvisessomjai, 2011. Three steps of one-way nested grid for energy balance equations by wave model. J. Comp. Math. Sci., 5: 23-30.

Wittmann, P.A. and P.D. Farrar, 1997. Global, regional and coastal wave prediction. Mar. Technol. Soc. J., 31: $76-82$. 